\title{
Extracts from Rhododendron ferrugineum Do Not Exhibit Grayanotoxin I: An Analytical Survey on Grayanotoxin I within the Genus Rhododendron
}

Authors

Affiliations
Matthias Lechtenberg $^{1 *}$, Frauke Dierks ${ }^{1 *}$, Jandirk Sendker ${ }^{1}$, Andrea Louis ${ }^{1}$, Hartwig Schepker $^{2}$, Andreas Hensel $^{1}$

${ }^{1}$ Institute of Pharmaceutical Biology and Phytochemistry, University of Münster, Münster, Germany

${ }^{2}$ Stiftung Bremer Rhododendronpark, Bremen, Germany
Key words

- Rhododendron ferrugineum

- Rhododendron

- Andromeda

- Kalmia

- Ericaceae

- grayanotoxin

- GC-MS received April 8, 2014

revised July 22,2014

accepted August 4, 2014

Bibliography

Dol http://dx.doi.org/

10.1055/s-0034-1383039

Published online September 12,

2014

Planta Med 2014; 80:

1321-1328 @ Georg Thieme

Verlag KG Stuttgart · New York .

ISSN 0032-0943

\section{Correspondence}

Prof. Dr. Andreas Hensel University of Münster

Institute of Pharmaceutical

Biology and Phytochemistry

Corrensstraße 48

48149 Münster

Germany

Phone: +492518333380

Fax: +492518338341

ahensel@uni-muenster.de

\section{Abstract}

$\nabla$

For quantitative determination of grayanotoxin I (1) in plant material, a GC/MS method was developed after trimethylsilyl derivatisation of the analytes. Forskolin (5) was used as an internal standard for quantification. ICH-compliant method validation indicated sufficient specificity, precision, quantitation $(15 \mu \mathrm{g} / \mathrm{mL})$ and detection $(5 \mu \mathrm{g} / \mathrm{mL})$ limits. Regression analysis showed that a non-linear (polynomial) model was preferable to a linear one. For isolation of grayanotoxin I reference material from Rhododendron ponticum leaves, an efficient two-step fast centrifugal partition chromatography isolation protocol is described. A survey of 17 different plant species from the genus Rhododendron revealed high grayanotoxin I content for $R$. catawbiense, $R$. ponticum, $R$. degronianum subsp. yakushimanum, $R . \times$ sochadzeae, $R$. moupinense, $R$. galactinum, and $R$. mucronatum var. ripense. The content of this compound in leaf material from $R$. ponticum de-

\section{Introduction}

$\nabla$

The leaves of Rhododendron ferrugineum L. (Ericaceae), a subalpine shrub found throughout the Pyrenees and the European Alps, have been traditionally used as aqueous decocts against rheumatism, blood pressure, muscle and metabolic diseases [1]. Recent data indicate antiviral effects against herpes simplex virus type 1 (HSV-1) [2]. However, evaluation by the German regulatory authorities indicated that these claims are not supported by sufficient clinical data [3]. Also potential toxicity due to hydroquinone and andromedotoxin and its derivatives could not be excluded, and a negative monograph was published

\footnotetext{
* Both authors contributed equally to this work.
}

creased rapidly during drying process. Grayanotoxin I was not detected in different batches of fresh leaves and fruits from $R$. ferrugineum. In contrast to the claims of German health authorities, this traditionally used herb therefore cannot be evaluated as toxic due to the presence of grayanotoxin I.

$\begin{array}{ll}\text { Abbreviations } \\ \text { BSTFA: } & \begin{array}{l}\text { N,O-bis(trimethylsilyl)trifluoroaceta- } \\ \text { mide }\end{array} \\ \text { FCPC: } & \begin{array}{l}\text { fast centrifugal partition chromatog- } \\ \text { raphy } \\ \text { grayanotoxin(s) }\end{array} \\ \text { GT: } & \text { grayanotoxin-I } \\ \text { GT-I: } & \text { internal standard } \\ \text { IS: } & \text { selected ion monitoring } \\ \text { SIM: } & \text { trimethylchlorosilane } \\ \text { TMCS: } & \text { trimethylsilyl } \\ \text { TMS: } & \end{array}$

[3], leading to a complete ban of the phytotherapeutic use of $R$. ferrugineum leaves.

Phytochemical investigation of the leaves from $R$. ferrugineum indicated the presence of triterpenes (ursolic acid, campanulin, friedelin, epifriedelin, $\alpha$ - and $\beta$-amyrin $[4,5]$, phenols (rhododendrin [6], phloracetophenon, and phloracetophenon-4-O-glucoside [7]), flavonoids (hyperoside, myricetin-3-O- $\beta$-galactopyranoside, kaempferol3-O-(6"-O-acetyl)-glucoside, quercetin-3-O-(6"$O$-acetyl)-glucoside, quercetin-3-O-(6"-O-acetyl)-galactoside, quercetin-3-O-(3",6"-O-diacetyl)-galactoside, cis- and trans-taxifolin-3-O- $\alpha$-Larabinopyranoside [8]), ferruginenes $A$ to $C$ [9], and short chain organic acids. Recently, the detailed composition of the volatile oil and of the flavonoid fraction, including the unusual quercetin-3-O-(6"-O-(2-methyl-1-oxobutyl))- $\beta$-D-glu- 


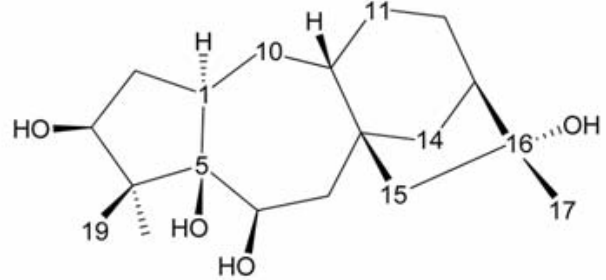

Grayanotoxins I-IV (1-

4)

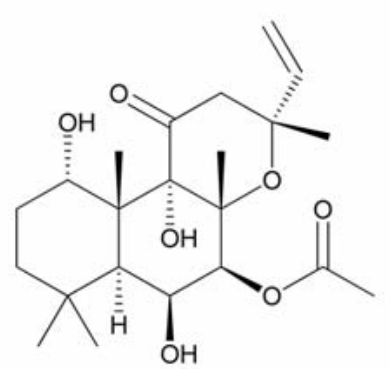

Forskolin (5)
Fig. 1 Structural features of grayanotoxins I to IV and forskolin.

\begin{tabular}{|c|c|c|c|c|c|}
\hline & \multicolumn{2}{|c|}{ Abbreviation } & $10 \beta$ & $10 \alpha$ & $14 \beta$ \\
\hline Grayanotoxin I & GT-I & 1 & $-\mathrm{CH}_{3}$ & $-\mathrm{OH}$ & $-\mathrm{OAc}$ \\
\hline Grayanotoxin II & GT-II & 2 & $=\mathrm{CH}_{2}$ & & $-\mathrm{OH}$ \\
\hline Grayanotoxin III & GT-III & 3 & $-\mathrm{CH}_{3}$ & $-\mathrm{OH}$ & $-\mathrm{OH}$ \\
\hline Grayanotoxin IV & GT-IV & 4 & $=\mathrm{CH}_{2}$ & & $-\mathrm{OAc}$ \\
\hline
\end{tabular}

copyranoside and $2 R, 3 R$-dihydromyricetin-3- $O-\beta$-L-arabinopyranoside, have been reported [10]. Flavan-3-ols (catechin, epicatechin, gallocatechin, epigallocatechin), oligomeric procyanidins (procyanidins B1 to B7 and C1), cinnamtannin B1, chlorogenic acid, monosaccharides (glucose, fructose), oligosaccharides (sucrose, stachyose, raffinose), fructan and polymeric type II arabinogalactan have been described in the same study as secondary metabolites from the leaves [10]. The presence of arbutin can be exluded $[10,11]$.

The literature concerning the presence of toxic diterpenic andromedan derivatives (GT) in leaves of $R$. ferrugineum is not conclusive. This has also been assessed by the German regulatory authorities [3]. Therefore, the present study aims to clarify unambiguously this still open question on the presence of GT in the leaf material by using validated chromatographic methods.

Andromedan diterpens, also called grayanans, are typical toxins from the Ericaceae plant family [12]. The basic $C_{20}$ structure (cf. - Fig. 1) can be modified with up to 8 hydroxyl groups, partially esterified with acetic-, lactic-, or propionic acid. Glucosides are rare, but known. The obligatory oxygen function at $\mathrm{C}-3$ can be functionalized as C-2,3-epoxy group. The different compounds will decompose to de-esterified products and also to unsaturated compounds after elimination of water, leading to the formation of olefinic derivatives [13]. The structural features of most common GT (GT-I to IV) from Ericaeae are displayed in $\bullet$ Fig. 1. GT-I (1, syn. andromedotoxin, acetylandromedol, rhodotoxin) is assessed to be the main native toxin, while the other GT originate from GT-I by degradation during senescence or drying processes.

GT-I exerts selective effects on voltage-dependent sodium channels by eliminating fast sodium inactivation and causing a hyperpolarizing shift in the voltage dependence of channel activation [14]. For GT intoxication, cholinergic symptoms are described, resulting in incapacitating and sometimes life-threatening brady- cardia, hypotension, and altered mental state. Complete heart failure occurs in a significant fraction of patients, and also asystole has been reported frequently [15]. The main source of intoxication with GT is honey (so called bitter or mad honey) from GT-containing nectar, frequently reported from the eastern Black Sea region of Turkey. For review on such frequent intoxications see [16-19]. For review on the actual toxicological assessment of GT and GT-containing products see [16]. For toxicological review on the genus Rhododendron see [20].

For quantification of GT, colorimetric methods after derivatisation with antimony salts [21], TLC [22], GC [23], HPLC with RI detection [24], and LC-MS [25] methods have been described, but a recent evaluation indicated [16] that until now no validated methods are known for the routine control of GT in plants and plant-derived products.

Therefore, the present study aimed at developing a validated and sensitive method to quantify GT-I in $R$. ferrugineum leaves and additionally to investigate representative species of the Rhododendron genus for the occurrence of GT.

\section{Results and Discussion}

$\nabla$

For systematic investigation of GT-I content in different species of the genus Rhododendron, especially in $R$. ferrugineum, a sensitive and validated method had to be established. As GT-I (1, ○ Fig. 1) was needed for analytical calibration without being commercially available, it was decided to isolate $\mathbf{1}$ from fresh leaves of Rhododendron ponticum L. for which GT-I is described to be the main naturally occurring GT [26]. Two different isolation procedures were used. Fractionation of dichloromethane soluble compounds, obtained from a hot methanol extract of the leaves material on aluminium oxide stationary phase as described by [27] 


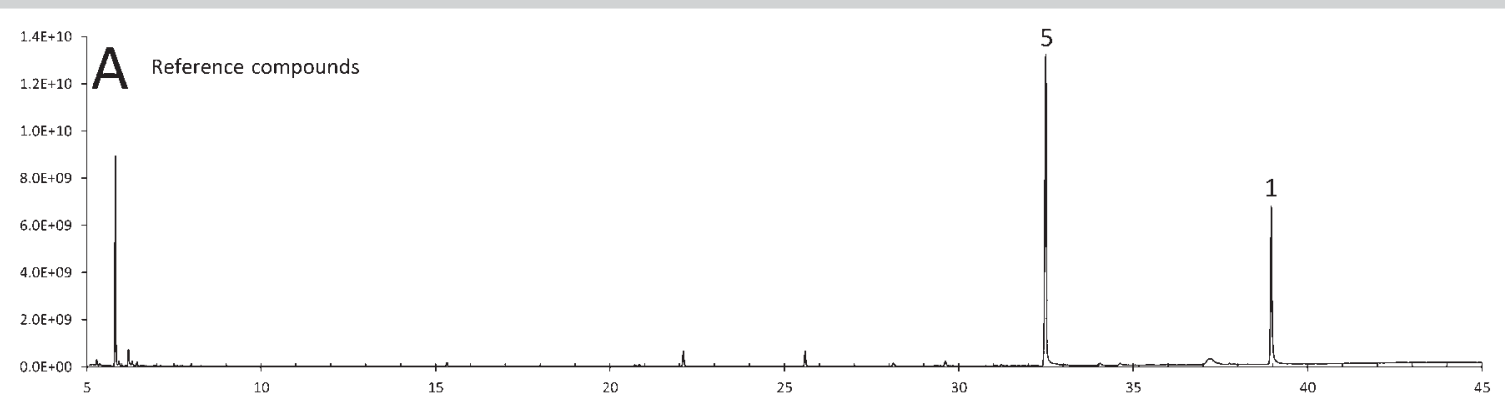

$\left.{ }_{7.0 E+07}^{8.0 E+07}\right] \mathbf{B}$ Rhododendron ponticum L. extract $(+1.5$.)
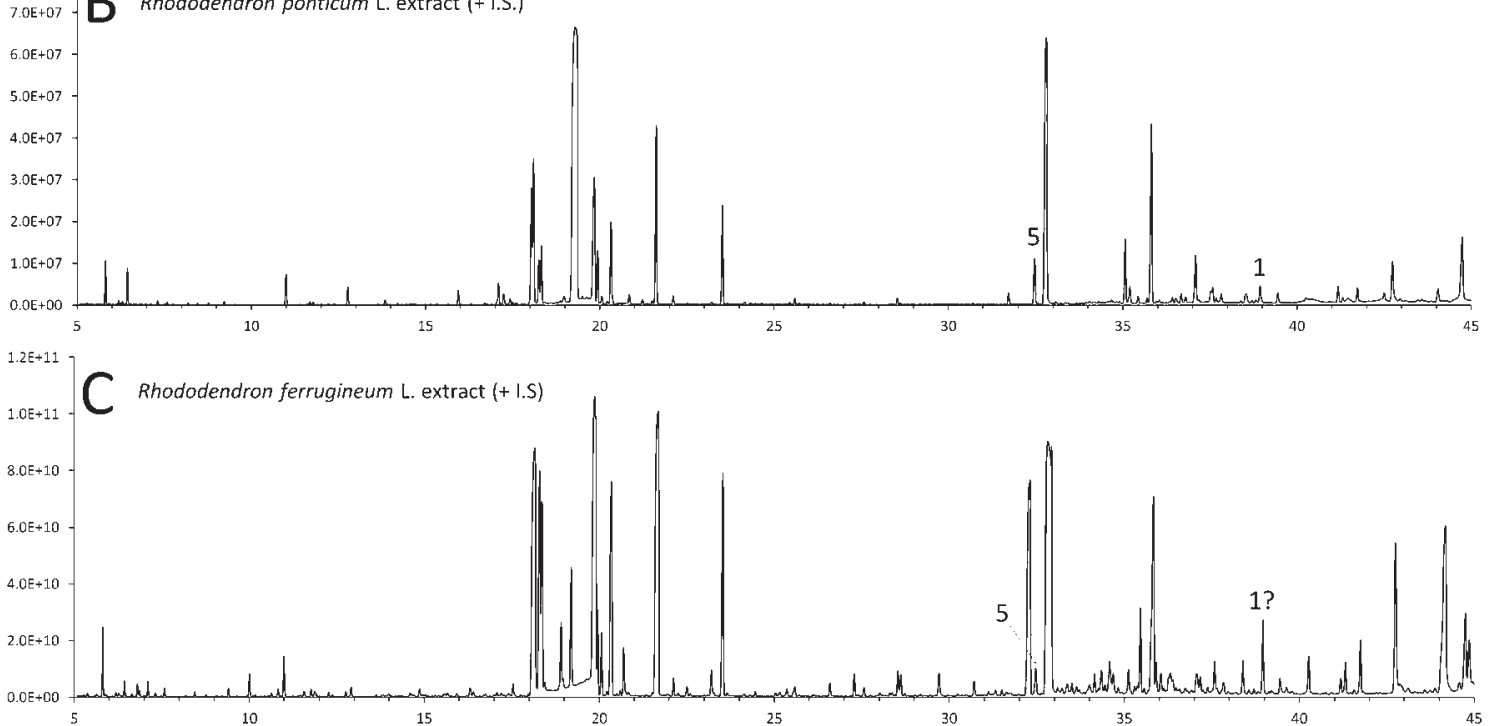

$6.0 \mathrm{E}+08$
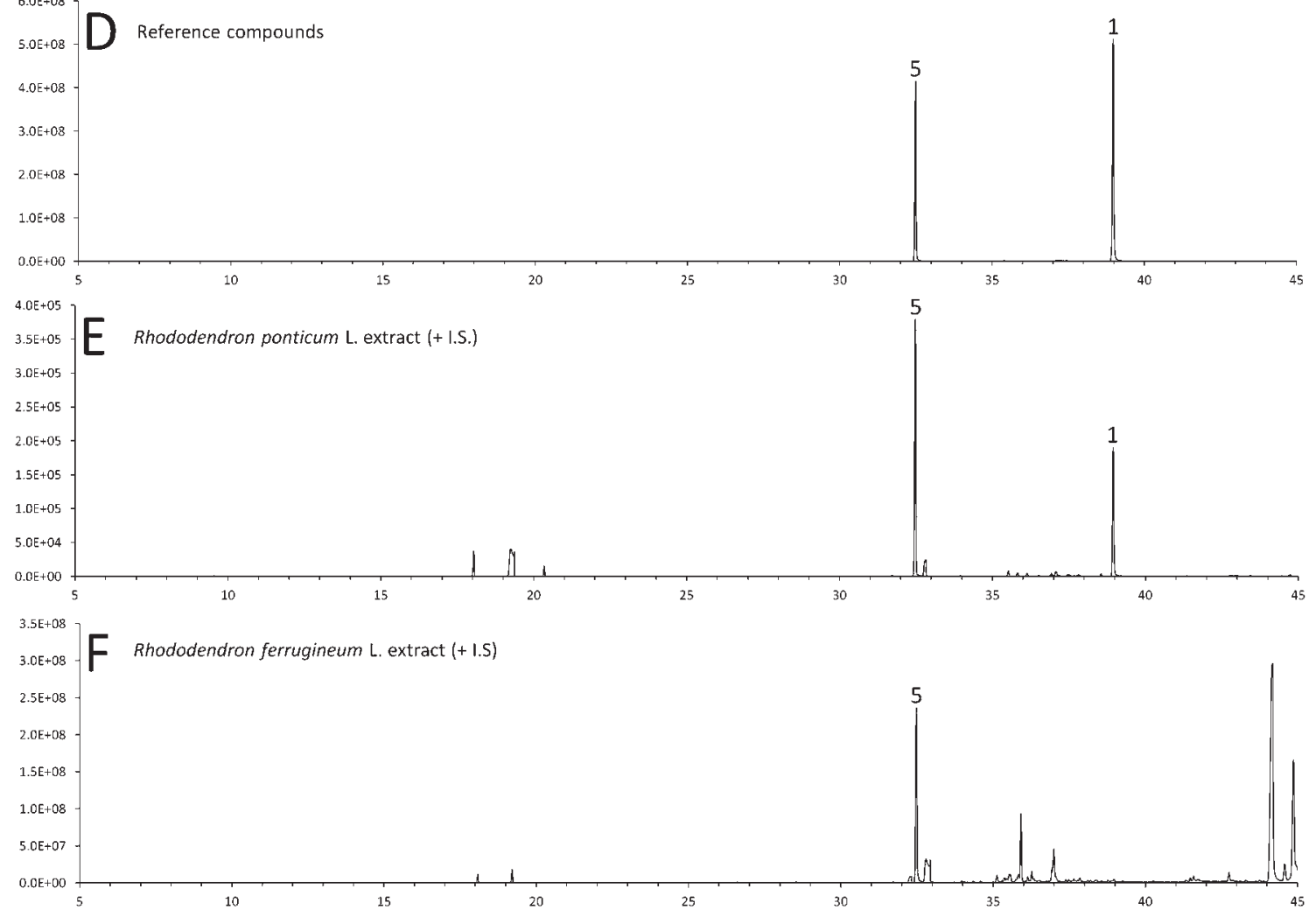

Fig. 2 Representative GC-MS chromatograms of silylated grayanotoxin I (1) found in the SCAN-mode can be definitely excluded to be 1 because of a difand internal standard forskolin (5) (A, D) and silylated leaf extracts from Rhododendron ponticum L. (B, E) and Rhododendron ferrugineum L. (C, F) in ferent mass spectrum and absence of specific signals at this retention time in SCAN-mode ( $\mathbf{A}$ to $\mathbf{C}$ ) and SIM-mode (D to $\mathbf{F})$. C The peak at $t_{R} 39$ min (1) 
yielded 1, but in not acceptable purity. For that, a two-step FCPC protocol was developed for the effective fractionation of dichloromethane-soluble compounds: the first step yielded a GT-I containing fraction in the upper phase, which was chromatographed again in a second solvent system so that pure GT-I could be isolated directly from the stationary phase and characterized concerning identity, purity, and content. This time-saving method resulted in good yields of 1 with considerable purity. The protocol is again a good example for the effectiveness of FCPC for rapid preparation of pure compounds as it has recently also been described for other pharmaceutically relevant compounds [2830].

For quantitation of $\mathbf{1}$ in plant materials, different methods were investigated: Due to the low UV-absorption of GT, HPLC with UV detection did not work sufficiently. Due to a very low ionization capacity of 1, the use of LC-MS did also not give promising results. Quantitative TLC with densitometric evaluation gave a clear and well separated spot for GT-I, but systematic evaluation during validation work raised significant problems concerning reproducibility and accuracy.

Sufficient results were obtained by GC-MS analysis of TMS-derivative of 1: Pre-experiments showed that only a combination of BSTFA, TMCS, and pyridine $(10: 1: 1, \mathrm{v} / \mathrm{v} / \mathrm{v})$ formed a stable and reproducible TMS-derivative. Pyridine was shown to be a mandatory (catalytic) part of the mixture. The silylation process was finished after $3 \mathrm{~h}$ at $70^{\circ} \mathrm{C}$ and resulted in a single peak in GC-MS analysis ( Fig. 2A). All attempts with alternative reagents (HMDS, MSTFA, or TMSI), varying volume proportions, or different temperature conditions failed or resulted in more than one silylated product.

The silylation mixture of 1 was analysed by means of high resolution FTMS. The experiment revealed two characteristic adduct ions $\left(\mathrm{m} / \mathrm{z} 708.4152[\mathrm{M}+\text { pyridine }+\mathrm{H}]^{+}\right.$and $\mathrm{m} / \mathrm{z} 651.3547$ $[\mathrm{M}+\mathrm{Na}]^{+}$) indicating a monoisotopic mass of $628.365 \mathrm{Da}$ $\left(\mathrm{C}_{31} \mathrm{H}_{60} \mathrm{O}_{7} \mathrm{Si}_{3}\right)$. Thus, three of five hydroxyl groups of 1 are silylated in the stable end-product. All attempts to vary the silylation protocols to obtain per-silylated $\mathbf{1}$ failed, and therefore it can be stated that under normal analytical silylation procedures, only the tri-substituted GT-I will be formed. On the other side the formation of this product, named $\mathbf{1}_{\mathrm{TMS}}$, was reproducible in all further validation series, and no hints occurred concerning potential over- or undersilylation.

$\mathbf{1}_{\text {TMS }}$ could easily be detected during GC-MS (EI) analysis; $\mathbf{1}_{\text {TMS }}$ revealed a base peak at $m / z 73\left(\left[\mathrm{Si}\left(\mathrm{CH}_{3}\right)_{3}\right]^{+}\right)$and a characteristic signal at $m / z 298$ (probably due to loss of all TMS-groups as well as multiple dehydration processes and elimination of the acetyl group). No peaks for $[\mathrm{M}]^{+}$or $[\mathrm{M}-15]^{+}$were detectable.

To improve the quantitation of the $\mathbf{1}_{\text {TMS }}$ derivative, the labdan diterpene forskolin $\mathbf{5}$ (for structural information of this compound, see $\bullet$ Fig. 1) was chosen as internal standard. The silylation end product $\mathbf{5}_{\text {TMS }}$ yielded one single peak in GC/MS ( $\bullet$ Fig. $2 \mathbf{A}$ ) and was also stable and reproducible under the given conditions.

For $\mathbf{5}_{\mathrm{TMS}}$ no signals for $[\mathrm{M}]^{++}$or $[\mathrm{M}-15]^{+}$were detectable, but $\mathbf{5}_{\mathrm{TMS}}$ showed a characteristic $m / z$ at 464 (probably due to elimination of water). The nominal mass of $\mathbf{5}_{\mathrm{TMS}}$ was determined to be $\mathrm{m} / \mathrm{z}$ 482 , indicating a mono-TMS derivative (see experimental part). A further significant improvement of the analytical method was obtained by using SIM-mode ( Fig. 2D to F) with $m / z 464$ for $\mathbf{5}_{\text {TMS }}$ and $m / z 298$ for $\mathbf{1}_{\text {TMS }}$ with better signal-to-noise ratio and selectivity in comparison to the SCAN-mode (- Fig. $2 \mathrm{~A}$ to $\mathbf{C}$ ). Therefore, GC-MS of $\mathbf{1}_{\text {TMS }}$ with $\mathbf{5}_{\text {TMS }}$ as IS in the SIM-mode was selected for validation and subsequent analysis of plant material.
Validation according to ICH-guidelines indicated the need of nonlinear calibration. The working range of the method was 15 to $600 \mu \mathrm{g}$ GT-I/mL, the limit of quantitation was $15 \mu \mathrm{g} / \mathrm{mL}$, and the detection limit $5 \mu \mathrm{g} / \mathrm{mL}$. System precision was determined with RSD 6.7\%, and repeatability from 6 independent samples was calculated with RSD 13\%. Stability of TMS-ethers in sample solution over $24 \mathrm{~h}$ was given.

Under certain conditions, the long-term storage of silylation mixtures resulted in decreasing measuring values. Hydrolysis of TMS-ethers - possibly caused by incoming humidity via the small puncture in the vial-septum - seems to play a central role especially in case of $\mathbf{1}$ : the ratio [Area 1/Area 5] decreased to approx. $60 \%$ of the initial value while injecting the solutions repeatedly over a period of $10-15 \mathrm{~h}$. To verify this assumption, we divided the test solution directly after the silylation process in two parts, injected the first immediately and the second, bottled in a sealed vial, after $24 \mathrm{~h}$ storage. In this case, good stability and no reduction of the ratio [Area 1/Area 5] were observed. Thus, storage of the silylation mixture under moisture-resistant conditions seems to avoid the described degradation of $\mathbf{1}_{\text {TMS }}$. Therefore, we decided to use one sealed vial only for one injection and furthermore a long-term storage of freshly prepared silylation-mixtures prior to injection had to be avoided.

For quantification of $\mathbf{1}$ in $R$. ferrugineum, the whole fresh plants, including soil blocks, were harvested at 3 different places in the Alps (Germany, Austria, and Italy) and transported within one day to the analytical laboratory where leaves and fruits were detached immediately. In all samples investigated, no signals for $\mathbf{1}_{\text {TMS }}$ were detectable under the described analytical conditions. From these data, we can exclude the presence of $\mathbf{1}$ in aerial material of $R$. ferrugineum above the quantitation limit and also the assessment of the German regulatory authorities [3] concerning this GT derivative should be revised. Therefore also the presence of degradation products $\mathbf{2}$ to $\mathbf{4}$ in the plant material can be excluded.

In order to investigate representative species of the Rhododendron genus on the occurrence of GT-I, fresh leaf material from 17 different defined species was investigated ( $\bullet$ Fig. 3 ).

The extreme variable genus Rhododendron consists of ca. 1000 species on four continents, which are classified in several subgenera, sections, and even subsections. The investigated species from the Rhododendron-Park Bremen belong to major groups within the genus, thereby representing the whole spectrum of variability. The selection includes evergreen and deciduous species, lepidote (= scaly) and elepidote (= non-scaly) species, small, bushy and large, tree-like species as well as azaleas. To avoid any impacts through hybridization, all of the chosen species are part of the German Genebank Rhododendron [31]. Species of this living gene bank have been identified by experts as being "true species" and are since then used as reference specimens.

Very high content of 1 was found for extracts from $R$. catawbiense Michx., a species native to North America, but also found heavily cultured in garden areas in Europe. In accordance with literature all samples from $R$. ponticum, native to Turkey and the Black Sea region, contained GT-I amounts from $0.13 \%$ to $0.22 \%$. This will easily explain the high toxicity of this plant and also of honey produced from this species. High values were found also for $R$. degronianum subsp. yakushimanum Carrière, native to Japan, and $R . x$ sochadzeae Char \& Davlianidze, a hybrid between $R$. ponticum $\times R$. caucasicum. GT-I values $<0.1 \%$ were determined for $R$. moupinense Franch., R. galactinum Balf. f. ex Tagg, and $R$. mucronatum var. ripense G. Don \& E. H. Wilson, all species com- 


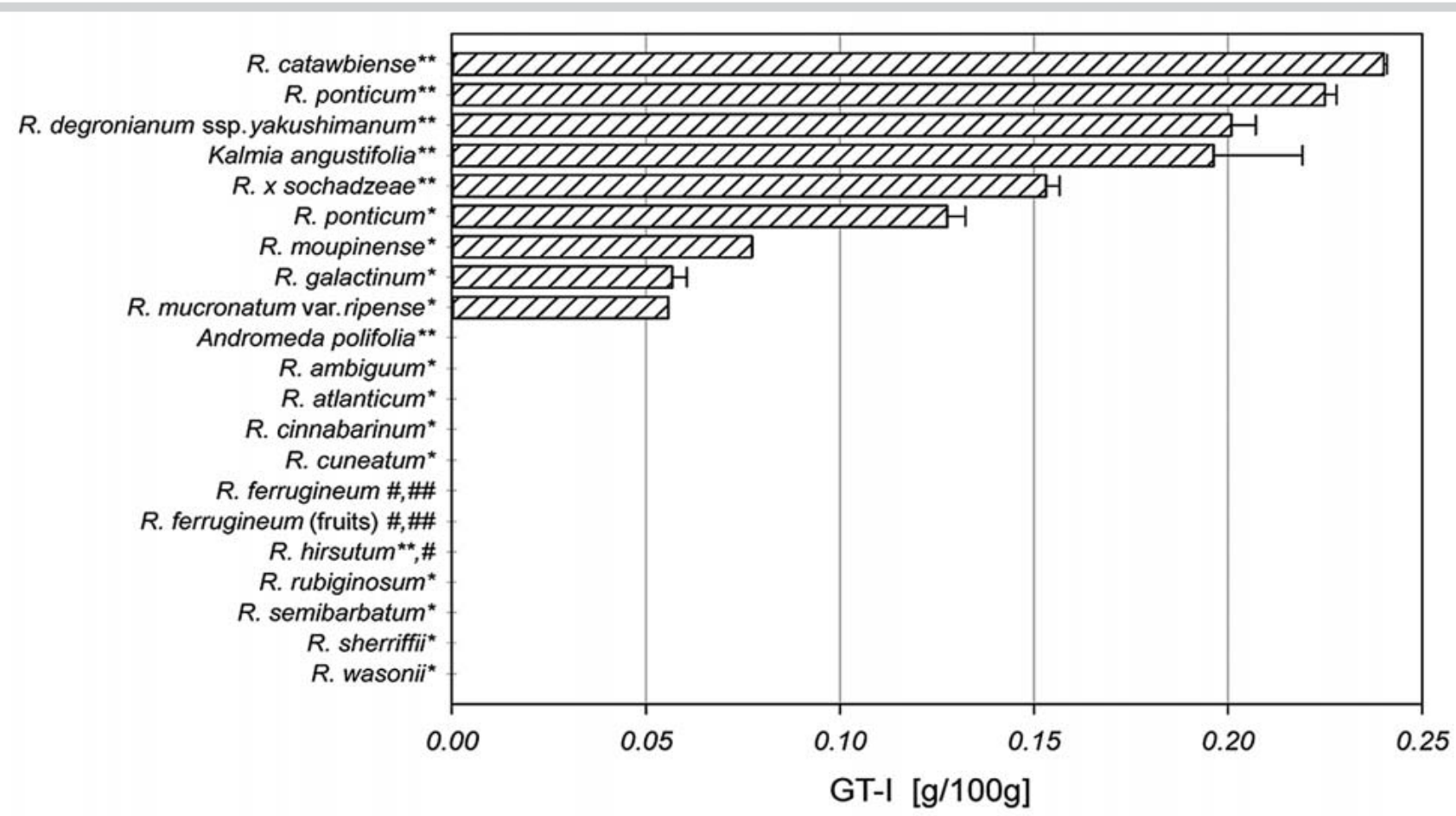

Fig. 3 GC-MS quantification of grayanotoxin I in different species from the genus Rhododendron, Kalmia angustifolia, and Andromeda polifolia. Bars represent upper and lower results from 2 independent determinations of representative samples. All data are given in g per $100 \mathrm{~g}$ fresh leaves. * Cultivated at Rhododendron Park, Bremen; * * cultivated at University of Münster; \# wild samples from collection at pre-Alps; \#\# wild samples from collection in central Alps. monly found in garden areas in Europe. All other Rhododendron species investigated had a GT-I content below the limit of detection $(30 \mathrm{ppm})$. Genera of Ericaceae closely related to the genera Rhododendron are Kalmia and Andromeda. While Andromeda polifolia L. did not contain 1, Kalmia angustifolia L. ("sheep-kill") had high content (about $0.2 \%$ ) of GT-I, which is in accordance with data reported by $[32,33]$.

From these data, it gets clear that the genus Rhododendron and related genera do not contain GT-I per se. The assessment on potential GT-I related toxicity within a distinct species has always to be done by distinct analytical investigation. For that, the here described method seems to be an efficient tool for a valid decision. Preliminary experiments [unpublished data] raised concerns on the stability of $\mathbf{1}$ in the plant material towards different drying conditions. For systematic investigation, representative leaf samples from $R$. ponticum were stored over a 18-days period at room temperature, and GT-I content was quantified at days $0,2,4,6,8$, and 18 under consideration of the respective water content of the plant material. As shown in $\odot$ Fig. 4, 1 was not stable during this drying process and degraded to about $30 \%$ related to the initial GT-I content as determined at day 0 . The same plant material, which had been lyophilized directly after harvesting showed higher GT-I content of about $55 \%$, related to the content of the freshly harvested leaf material. At this point of the investigation, it got obvious that GT-I seems to degrade quite fast after harvesting and during drying process, and therefore air-dried leaf material from $R$. ponticum stored for a longer time (harvested in Turkey in 2010 and carefully stored at room temperature since then) was investigated: in this case, GT-I content was - as expected below the limit of detection.

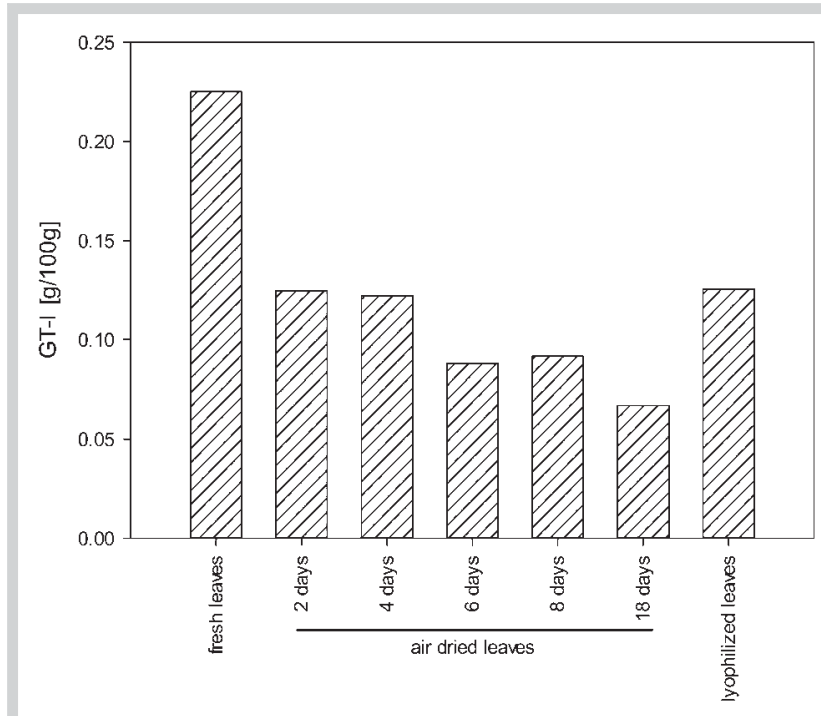

Fig. 4 Influence of drying process on grayanotoxin I content in leaves from Rhododendron ponticum. A representative sample of freshly harvested leaves was air-dried over an 18-days period or was lyophilized (rightmost bar). GT-I content was calculated by GC-MS analysis and given in $\mathrm{g}$ per $100 \mathrm{~g}$ (fresh leaves).

From these investigations, the contradictory data about the distribution of GT in different species of the genus Rhododendron [34] have been clarified to a wide extent. Especially in case of $R$. ferrugineum there was need for clarification because a potential toxicity due to GT could not to be excluded, and the publica- 
tion of a monograph [3] led to a complete restriction of any phytotherapeutic use of $R$. ferrugineum leaves.

In conclusion, the results indicate that GT-I, the genuine and predominant GT derivative, is not present in freshly harvested leaves and fruits from $R$. ferrugineum above the limit of detection (30 ppm). By analogy, potential degradation products (GT-II, GT-III, GT-IV) are neither present. Thus, the still open question on the presence of GT in the leaf material of $R$. ferrugineum was answered using a validated chromatographic GC-MS method.

The data corroborate the fact that GT-I is not stable during common drying processes. Even freeze-dying reduces the amount of GT-I considerably. Thus, GT-I (and its artefacts) may not be detected in long term stored plant material, which may be the reason for the described contradictory literature data in the genus Rhododendron.

Furthermore, it was shown that GT-I is detectable in high amounts $(\geq 0.15 \%)$ in some species of the genus Rhododendron, namely $R$. catawbiense, $R$. ponticum, $R$. $x$ sochadzeae, and $R$. degronianum subsp. yakushimanum. Leaves of some other Rhododendron species ( $R$. moupinense, $R$. galactinum, and $R$. mucronatum var. ripense) contain slightly lower contents (0.05-0.1\%).

\section{Materials and Methods}

$\nabla$

General analytical techniques

If not stated otherwise, chemicals were obtained in analytical quality from VWR.

\section{Plant material}

Voucher samples are stored in the archives of the Institute of Pharmaceutical Biology and Phytochemistry, University of Münster, Germany; IPBP registration numbers are given in braces.

Plant material from different sources was used:

[A] Cultivated plants:

- Medicinal Plant Garden of the Institute of Pharmaceutical Biology and Phytochemistry, University of Münster, Germany: Rhododendron catawbiense Michx. \{IPBP 347\}, R. degronianum subsp. yakushimanum Carrière \{IPBP 348\}, R. hirsutum L. \{IPBP 349\}, R. ponticum L. \{IPBP 350\}, R. x sochadzeae Char \& Davlianidze \{IPBP 351\}, Andromeda polifolia L. \{IPBP 352\}, Kalmia angustifolia L. \{IPBP 353\}. Plants were collected in 2013 by FD, ML and identified by Lars Krüger.

- Rhododendron Park, Bremen, Germany. Numbers in round brackets indicate the accession number in the German Gene Bank Rhododendron [31]: R. ambiguum Hemsl. (100007) \{IPBP 354\}, R. ponticum L. (100393) \{IPBP 355\}, R. wasonii Hemsl. \& E.H. Wilson (100799) \{IPBP 356\}, R. cinnabarinum Hook. f. (100322) \{IPBP 357\}, R. moupinense Franch. (100374) \{IPBP 358\}, R. rubiginosum Franch. (100404) \{IPBP 359\}, R. atlanticum (Ashe) Rehder (100013) \{IPBP 360\}, R. semibarbatum Maxim. (100781) \{IPBP 361\}, R. cuneatum W.W. Sm. (100328) \{IPBP 362\}, R. sherriffii Cowan. (100795) \{IPBP 363\}, R. mucronatum var. ripense E.H. Wilson (100402) \{IPBP 364\}, R. galactinum Balf. f. ex Tagg (100349) \{IPBP 365\}. Plants were collected and identified in 2013 by HS.

[B] Wild harvested plants from botanical excursions:

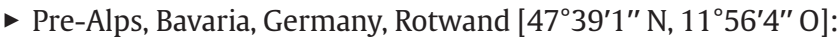
leaves from $R$. hirsutum L. \{IPBP 366\} and $R$. ferrugineum L. \{IPBP 367\}. Plants were collected and identified in May 2011 by $\mathrm{AH}$.
- Central Alps, Italy, Hochfeiler 1, Hochfeiler 2 [46 $56^{\circ} 21^{\prime \prime} \mathrm{N}, 11^{\circ}$ $\left.43^{\prime} 39^{\prime \prime}\right]$ and Austria, south-western part of Zillertal [ $47^{\circ} 18^{\prime} 28^{\prime \prime}$ $\mathrm{N}, 11^{\circ} 52^{\prime} 27^{\prime \prime}$ O]: leaves \{IPBP 368/370 $\}$ and fruits \{IPBP 369/ $371\}$ from $R$. ferrugineum L. Plants were collected and identified in July 2013 by $\mathrm{AH}$.

- Turkey, air dried leaves from $R$. ponticum L. \{IPBP 372\} were collected and identified in 2010 by Belmar Konuklugil, University of Ankara.

\section{Isolation of grayanotoxin I (1)}

GT-I (1, 0 Fig. 1) is the main naturally occurring GT derivative in leaves of Rhododendron ponticum. As it is not commercially available, it was decided to isolate $\mathbf{1}$ from fresh leaves of this plant. Two different isolation procedures were used.

Extraction of plant material, according to [27]: Fresh leaves were harvested and stored at $-18^{\circ} \mathrm{C} .150 \mathrm{~g}$ of powdered plant material were extracted with $400 \mathrm{~mL}$ hot methanol for $1 \mathrm{~h}$ under reflux. After filtration, solvent was removed by rotary evaporation, and the dried extracts were partitioned between water and dichloromethane. Combined organic phases were taken to dryness to yield extracts E1 and E2 (originating from 2 independent extraction procedures). Following, two different isolation procedures for 1 were tested.

Isolation procedure A, based on [27]: Fractionation of E1 was done by column chromatography (stationary phase: neutral $\mathrm{Al}_{2} \mathrm{O}_{3}$; $500 \times 20 \mathrm{~mm}$; mobile phase: chloroform/methanol $9: 1, \mathrm{v} / \mathrm{v}$; flow: $1.75 \mathrm{~mL} / \mathrm{min}$; fraction size: $2.5 \mathrm{~min}$ ). Fractions 61 to 72 , corresponding to 267 to $315 \mathrm{~mL}$ of mobile phase, containing 1 were combined according to TLC analysis (see below) to yield $34.2 \mathrm{mg}$. Further purification was achieved by preparative HPLC (Waters 515 pump, UV detector (Knauer), stationary phase: Eurospher ${ }^{\circledR}$ $100 \mathrm{C} 18$ (Knauer), $7 \mu \mathrm{m}, 250 \times 20 \mathrm{~mm}$; mobile phase: $\mathrm{CH}_{3} \mathrm{CN} /$ water gradient, $5: 95 \rightarrow 100: 0$ in $40 \mathrm{~min}$; flow $9 \mathrm{~mL} / \mathrm{min}$; fraction size $0.5 \mathrm{~min}$; detection wavelength $200 \mathrm{~nm}$;) to yield $13.2 \mathrm{mg}$ (yield: $0.009 \%$ referred to fresh leaves). The isolated product was identified by MS and NMR as 1. Purity was insufficient for use as standard for quantification $(<80 \%)$.

Isolation procedure $B$ : Fractionation of $\mathrm{E} 2$ was performed by FCPC. The FCPC conditions were as follows: CPC Kromaton ${ }^{\circledR}$, (Kromaton Technologies), system A: EtOAc/ $\mathrm{H}_{2} \mathrm{O}(1+1)$; system B: heptane/ ethyl acetate/methanol/water $(1+1+1+1)$; mobile phases = upper phases; flow: $10 \mathrm{~mL} \cdot \mathrm{min}^{-1} ; 1200 \mathrm{rpm}$, fraction size: $1 \mathrm{~min}$. Fractions were combined according to TLC analysis (TLC system as described below). Separation system A yielded $70 \mathrm{mg}$ of a GT-I enriched fraction. Further purification was subsequently achieved by separation system B. Evaporation of the lower (stationary) phase $(200 \mathrm{~mL})$ of separation system B which could easily be pumped out from the FCPC at the end of the run yielded $12.6 \mathrm{mg}$ in $80-90 \%$ purity as proven by NMR spectroscopy (see below). Subsequent column chromatography of this fraction yielded $6.7 \mathrm{mg}$ of pure compound 1 (named GT-I $\mathrm{I}_{\mathrm{RS}}$ ). Parameters of CC: silica gel 60 (Merck No.5554), 0.063-0.200 mm; $500 \times 20 \mathrm{~mm}$; step gradient: hexane, ethyl acetate, and methanol.

\section{Reference standards}

$G T-I_{R S}(1)$ : identity of 1 was confirmed by means of LC-ESIQTOF-MS/MS and ${ }^{13} \mathrm{C}-\mathrm{NMR}$ [32]. TLC $\mathrm{R}_{\mathrm{f}}$ value: 0.42 . The purity of GT-I $\mathrm{I}_{\mathrm{RS}}$ was determined by means of TLC-densitometry ( 5 to $17.5 \mu \mathrm{g}$ of GT-I $\mathrm{RS}_{\text {R }}$ ) after spraying with $60 \% \mathrm{H}_{2} \mathrm{SO}_{4}$ and heating. Remission was measured at different wavelengths. The purity was determined to be $89.9 \%$. Parameters: TLC conditions, see below; 
densitometer, Desaga CD60 (Wiesloch); measurement of remission at $\lambda 600,530$, and $254 \mathrm{~nm}$, Kubelka-Munk correction. GT-III (3): andromedol-hemi(ethyl acetate) adduct, Sigma-Aldrich. TLC $R_{f}$ value: 0.42 . Because of its limited purity (<90\%), 3 was only used as TLC-reference standard.

Forskolin (5): purity > 98\% (according specification of manufacturer), J63292, Lot E21Z044, Alfa Aesar GmbH.

\section{Chromatographic and spectroscopic methods}

TLC, according to [35]: Silica gel $60 \mathrm{~F}_{254}$, Merck No. 5554, mobile phase: ethyl acetate-methanol-water $(81+11+8$, v/v/v); vol.: 2$10 \mu \mathrm{L}$, applied as band; detection: sulfuric acid, $60 \%, 100^{\circ} \mathrm{C}$, $2 \mathrm{~min}$, UV $\lambda=366 \mathrm{~nm}$ and daylight.

QTOF-MS/MS and high resolution FTMS: LC-ESI-QTOF-MS/MS: Dionex Ultimate 3000 RS liquid chromatography system, Dionex Acclaim RSLC 120 (Thermo Scientific), C18 stationary phase $(2.2 \times 100 \mathrm{~mm})$, binary gradient (A: water with $0.1 \%$ formic acid; B: acetonitrile with $0.1 \%$ formic acid), flow: $0.8 \mathrm{~mL} \cdot \mathrm{min}^{-1}$ : 0 to 9.5 min: linear from $5 \%$ B to $100 \%$ B; injection volume $1-2 \mu \mathrm{L}$; Bruker Daltonics micrOTOF-QII time-of-flight mass spectrometer, Apollo electrospray ionization source in positive mode at $5 \mathrm{~Hz}$, mass range $\mathrm{m} / \mathrm{z} 50-1000$. The spectrum of 1 showed characteristic $m / z$ values: $847.4068[2 \mathrm{M}+\mathrm{Na}]^{+}, 430.2802\left[\mathrm{M}+\mathrm{NH}_{4}\right]^{+}$, $395.2429\left[\left(\mathrm{M}-\mathrm{H}_{2} \mathrm{O}\right)+\mathrm{H}\right]^{+}, 377.2323\left[\left(\mathrm{M}-2 \mathrm{H}_{2} \mathrm{O}\right)+\mathrm{H}\right]^{+}, 359.4766$ $\left[\left(\mathrm{M}-3 \mathrm{H}_{2} \mathrm{O}\right)+\mathrm{H}\right]^{+}$.

APCI-QTOF-MS/MS: Direct probe experiments of the TMS derivatives (silylation protocol described below) of $\mathbf{1}$ and $\mathbf{5}$ (named $\mathbf{1}_{\mathrm{TMS}}$ and $\mathbf{5}_{\mathrm{TMS}}$ ) in APCI mode revealed the grade of silylation. $\mathrm{m} / \mathrm{z}$ values: $\mathbf{1}_{\mathrm{TMS}} 708.418[\mathrm{M}+\text { pyridine }+\mathrm{H}]^{+}$and $629.372[\mathrm{M}+\mathrm{H}]^{+}$indicating three silylated $\mathrm{OH}$-groups $\left(\mathrm{C}_{31} \mathrm{H}_{60} \mathrm{O}_{7} \mathrm{Si}_{3}\right) ; \mathbf{5}_{\mathrm{TMS}}: 562.318$ $[\mathrm{M}+\text { pyridine }+\mathrm{H}]^{+}$and $483.274[\mathrm{M}+\mathrm{H}]^{+}$indicating one silylated OH-group $\left(\mathrm{C}_{25} \mathrm{H}_{42} \mathrm{O}_{7} \mathrm{Si}\right)$.

High resolution FTMS: Orbitrap LTQ XL (Thermo Scientific), ESI, positive mode, full $\mathrm{ms}, 150-2000 \mathrm{Da}$. Characteristic $m / z$ - values of $\mathbf{1}_{\mathrm{TMS}}$ : $708.4152[\mathrm{M}+\text { pyridine }+\mathrm{H}]^{+}\left(\mathrm{C}_{31} \mathrm{H}_{60} \mathrm{O}_{7} \mathrm{Si}_{3} \mathrm{C}_{5} \mathrm{H}_{5} \mathrm{NH}\right)$ and $651.3547[\mathrm{M}+\mathrm{Na}]^{+}\left(\mathrm{C}_{31} \mathrm{H}_{60} \mathrm{O}_{7} \mathrm{Si}_{3} \mathrm{Na}\right)$.

\section{${ }^{13} \mathrm{C}-\mathrm{NMR}$ spectroscopy}

Varian 600 Unity Plus. Fraction GT-I $\mathrm{I}_{\mathrm{FCPC}}$ was measured in pyridine- $\mathrm{d}_{5}$. Reference signal: pyridine- $\mathrm{d}_{5}$ at $\delta 123.5 \mathrm{ppm}$. $\delta$ of carbon signals in ppm: 51.39 (C1), 35.83 (C2), 82.61 (C3), 51.76 (C4), 84.45 (C5), 73.73 (C6), 44.11 (C7), 51.03 (C8), 55.62 (C9), 77.94 (C10), 22.45 (C11), 27.36 (C12), 55.04 (C13), 82.82 (C14), 61.18 (C15), 78.55 (C16), 23.97 (C17), 23.39 (C18), 19.80 (C19), 28.30 (C20), 170.35 (C21), 21.22 (C22).

\section{Quantification of 1 in plant material}

Plant material (e.g., leaves) was grounded in a mortar by use of liquid $\mathrm{N}_{2}$. An aliquot (0.9-1.1 g) was exactly weighted and extracted with $10 \mathrm{~mL}$ methanol in a $15 \mathrm{~mL}$ falcon-tube. The suspension was ultra-sonicated for $90 \mathrm{~min}$ and centrifuged at $6500 \times \mathrm{g}$ for $5 \mathrm{~min}$. An aliquot of $500 \mu \mathrm{L}$ was used for subsequent silylation. $500.0 \mu \mathrm{L}$ of the extract and $100.0 \mu \mathrm{L}$ of an IS-stock solution (containing $0.5 \mathrm{mg} \cdot \mathrm{mL}^{-1}$ of 5 in methanol) were taken to dryness under a stream of nitrogen gas. $25.0 \mu \mathrm{L}$ pyridine, $25.0 \mu \mathrm{L}$ TMCS (Machery \& Nagel), and 250.0 $\mu$ L BSTFA (Machery \& Nagel) were added. The mixture was heated in a sealed vial for $3 \mathrm{~h}$ at $70.0^{\circ} \mathrm{C}$ on a hotplate. The temperature was controlled with an adjustable contact thermometer.
GC-MS analysis of silylated grayanotoxin I in plant extract $1 \mu \mathrm{L}$ of the silylation-mixture was analysed in a 6890 N GC System with Agilent 5973 mass selective detector (single quad.) (Agilent Technologies). Mobile phase: He; stationary Phase: HP-5MS $(30 \mathrm{~m} \times 0.25 \mathrm{~mm} \times 0.25 \mu \mathrm{m})$; temp. gradient: $100^{\circ} \mathrm{C}$ to $310^{\circ} \mathrm{C}\left(5^{\circ} \mathrm{C} / \mathrm{min}\right), 15 \mathrm{~min}$ isothermal; EI $-70 \mathrm{eV}$; SCAN mode and SIM mode (for quantitative determination). SIM-mode: 0 $34 \mathrm{~min}: \mathrm{m} / \mathrm{z}=464 ; 35-45 \mathrm{~min}: \mathrm{m} / \mathrm{z}=298$. The retention times were as follows: $\mathbf{5}_{\mathrm{TMS}}=\mathbf{3 2 . 5} \mathrm{min}, \mathbf{1}_{\mathrm{TMS}}=39.0 \mathrm{~min}$. The following relevant mass fragments of the silylated compounds $\mathbf{1}$ and $\mathbf{5}$ were recorded:

$1_{\text {TMS }}$ m/z (\%), 520 (1), 460 (2), 430 (7), 388 (7), 370 (12), 358 (11), 299 (11), 298 (40), 255 (8), 207 (16), 183 (8), 157 (9), 145 (15), 143 (13), 133 (11), 117 (20), 75 (48), 73 (100), 43 (25).

5 TMS: $m / z(\%), 464$ (58), 436 (3), 354 (3), 353 (4), 331 (6), 279 (14), 237 (14), 219 (15), 209 (13), 191 (42), 177 (20), 165 (22), 163 (19), 129 (32), 123 (36), 109 (26), 107 (21), 95 (32), 81 (31), 73 (78), 43 (100).

\section{Analytical validation, according to [36]}

Identity: Peak identification of 1 and 5 was ensured by the respective GC/MS-spectra and by co-injection with reference standards.

Non-linear calibration: Stock solutions (in methanol): 1 (GT-I $\mathrm{RS}_{\mathrm{RS}}$ $0.50 \mathrm{mg} \cdot \mathrm{mL}^{-1} ; 5$ (IS) $0.51 \mathrm{mg} \cdot \mathrm{mL}^{-1}$. Concentrations in measured samples (after silylation, with consideration of purity of GT-I $\mathrm{I}_{\mathrm{RS}}$ ): 1: $15-600 \mu \mathrm{g} \cdot \mathrm{mL}^{-1}$; IS 5: $340 \mu \mathrm{g} \cdot \mathrm{mL}^{-1}$ in each case. Analysis of data showed that a polynomic (quadratic) regression was preferable to a linear one. This was also supported by Mandel's fitting test [37]; calibration curve [y=area $1 /$ area $5 ; \mathrm{x}=$ conc. $1 /$ conc. 5$]$ : $\mathrm{y}=0.5084 \mathrm{x}^{2}-0.1631 \mathrm{x}+0.0258\left(\mathrm{R}^{2}=0.9988\right)$.

Range: 15 to $600 \mu \mathrm{g} \cdot \mathrm{mL}^{-1}$ of 1 in sample solution (the volume of silylation mixture was $300 \mu \mathrm{L}$ in each case).

Quantitation limit (LOQ), based on the calibration curve:

$15 \mu \mathrm{g} \cdot \mathrm{mL}^{-1}$ of 1 in sample solution (equal to $90 \mathrm{mg}$ per $\mathrm{kg}$ plant material).

Detection limit (LOD), based on signal-to-noise approach:

$5 \mu \mathrm{g} \cdot \mathrm{mL}^{-1}$ of 1 in sample solution (equal to $30 \mathrm{mg}$ per $\mathrm{kg}$ plant material).

Precision: Repeatability (system precision) was determined to be $6.7 \%$. The intra-assay precision was $13.7 \%$ (\% RSD), determined under the same conditions performed with double injections of 6 independent sample preparations.

\section{Drying experiments}

Air drying: Some representative leaves of Rhododendron ponticum were harvested in the Medicinal Plant Garden of the Institute and stored in the lab at room temperature under protection from direct daylight. In order to determine the average loss of water, all individual leaf weights were measured at day 0 (= initial fresh weight), 2, 4, 6, 8, and 18 (= dry weight) and averaged for each measuring day. The mean values of weight loss $(\mathrm{WL})$ were as follows: day 2: $40.3 \% \mathrm{WL}(27 \% \mathrm{RSD}, \mathrm{n}=22)$, day $4: 56.6 \% \mathrm{WL}$ (19\% RSD, $n=20)$, day 6: 66.7\% WL (10\% RSD, $n=19)$, day 8: 69.3\% WL (10\% RSD, $n=15)$, and day 18: 71.5\% WL (9\% RSD, $\mathrm{n}=14$ ). Relative water contents (RWC) were as follows: day 2 : $46.3 \%$; day 4 : $24.6 \%$, day 6 : $11.1 \%$, day $8: 7.6 \%$, day $18: 4.7 \%$. At each examination day a random leaf sample was taken from the population, grounded in a mortar by use of liquid $\mathrm{N}_{2}$ and analysed by means of GC/MS as described above. In order to be able to compare the results with fresh leaves, the amount of 1 was cal- 
culated based on consideration of the respective amount of water loss at each measuring day.

Freeze drying: In a parallel experiment, a collection of some representative leaves were freeze dried. The loss of water was determined to be $75 \%$.

\section{Acknowledgements}

$\nabla$

Technical assistance of Mrs. Bettina Quandt and Mr. Lars Krüger is acknowledged. Thanks to our undergraduate students G.F. Born, M. Goldstein, M. Schmitt, and C. Wessel who contributed during an internship for preliminary studies on isolation procedures and the best silylation method. Thanks to Prof. Dr. Belmar Konuklugil, University of Ankara, Turkey, for providing leaf material from $R$. ponticum and to Prof. Dr. T.S. Schmidt for fruitful discussion. Many thanks are due to Dr. H. Luftmann (Institute of Organic Chemistry, Münster) for high resolution FTMS measurements and Dr. J. Köhler (Institute of Phamaceutical and Medicinal Chemistry, Münster) for NMR experiments.

\section{Conflict of Interest}

$\nabla$

The authors declare no conflicts of interest.

\section{References}

1 Goez C. Rhododendron ferrugineum L. In: Hänsel R, Keller K, Rimpler H, Schneider G, editors. Hagers Handbuch der Pharmazeutischen Praxis, 5th edition. Berlin, Heidelberg: Springer; 1994: 444-449

2 Gescher K, Kühn J, Hafezi W, Louis A, Derksen A, Deters A, Lorentzen E, Hensel $A$. Inhibition of viral adsorption and penetration by an aqueous extract from Rhododendron ferrugineum L. as antiviral principle against herpes simplex virus type-1. Fitoterapia 2011; 82: 408-413

3 German Commission E Monographs. Evaluation monograph Rhododendri ferruginei folium. Cologne: Bundesanzeiger; 1990: 164

4 Passerini M, Ridi M, Papini P. Some substances isolated from plant extracts. Ann Chim 1954; 44: 783-786

5 Fokina GA, Belova NV, Gorovoi PG. Triterpenoids from Rhododendron kamtschaticum and Rhododendron ferrugineum. Khim Prir Soedin 1971; 7: 377

6 Thieme H, Winkler H. Beitrag zur chemotaxonomischen Bedeutung des Vorkommens von Rhododendrin in der Gattung Rhododendron. Pharmazie 1969; 24: 703

7 Chosson E, Chaboud A, Chulia AJ, Raynaud J. A phloracetophenone glucoside from Rhododendron ferrugineum. Phytochem 1998; 47: 87-88

8 Chosson E, Chaboud A, Chulia AJ, Raynaud J. Dihydroflavonol glycosides from Rhododendron ferrugineum. Phytochem 1998; 49: 1431-1433

9 Seephonkai P, Popescu R, Zehl M, Krupitza G, Urban E, Kopp B. Ferruginenes A-C from Rhododendron ferrugineum and their cytotoxic evaluation. J Nat Prod 2011; 74: 712-717

10 Louis A, Petereit F, Lechtenberg M, Deters A, Hensel A. Phytochemical characterization of Rhododendron ferrugineum and in vitro assessment of an aqueous extract on cell toxicity. Planta Med 2010; 76: 1550-1557

11 Sticher 0 , Soldati F, Lehmann D. High-performance liquid chromatographic separation and quantitative determination of arbutin, methylarbutin, hydroquinone and hydroquinone-monomethylether in Arctostaphylos, Bergenia, Calluna and Vaccinium species. Planta Med 1979; 35: 253-261

12 Teuscher E, Lindequist U. Biogene Gifte, 3rd edition. Stuttgart: Wissenschaftliche Verlagsgesellschaft; 2010: 177-180

13 Plugge PC. Andromedotoxinhaltige Ericaceen. Arch Pharm 1891; 229: 552-554

14 Maejima H, Kinoshita E, Seyama I, Yamaoka K. Distinct sites regulating grayanotoxin binding and unbinding to $\mathrm{D} 4 \mathrm{~S} 6$ of $\mathrm{Na}(\mathrm{v}) 1.4$ sodium channel as revealed by improved estimation of toxin sensitivity. J Biol Chem 2003; 278: 9464-9471
15 Gunduz A, Turedi S, Russell RM, Ayaz A. Clinical review of grayanotoxin/ mad honey poisoning past and present. Clin Tox 2008; 46: 437-442

16 Bundesamt für Risikobewertung. Cases of poisoning through grayanotoxins in rhododendron honey originating from the Turkish Black Sea Region. BfR risk assessment No.043/2010 from September 3, 2010. Available at http://www.bfr.bund.de/cm/343/vergiftungsfaelle_durch_ grayanotoxine_in_rhododendron_honigen_aus_der_tuerkischen_ schwarzmeerregion.pdf. Accessed July 20, 2014.

17 Demir H, Denizbasi A, Onur O. Mad honey intoxication: a case series of 21 patients. ISRN Toxicol 2011: 2011: Article ID 526426 (3 pages)

18 Demircan A, Keles A, Bildik F, Aygencel G, Doğan NO, Gómez HF. Mad honey sex: therapeutic misadventures from an ancient biological weapon. Ann Emerg Med 2009; 54: 824-829

19 Uzun, H, Narci H, Tayfur I, Karabulut KU, Karioglu O. Mad honey intoxication: what is wrong with the blood glucose? A study on 46 patients. Eur Rev Med Pharmacol Sci 2013; 17: 2728-2731

20 Popescu R, Kopp B. The genus Rhododendron: an ethnopharmacological and toxicological review. J Ethnopharmacol 2013; 147: 42-62

21 Zymalkowski F, Pachaly P, auf dem Keller S. Die Bestimmung von Acetylandromedol (Grayanotoxin I) in Extrakten von Rhododendron ponticum. Planta Med 1969; 17: 8-13

22 Terai T. Determination of grayanotoxin I, II and III by thin-layer chromatography. J Agricul Chem Soc Japan (Nihon Nogei Kagakkai-shi) 1987; 58: 1117-1122

23 Terai T, Uda T, Katakawa J, Tetsumi T. Assay of grayanotoxins by gas chromatography. Nippon Nogeikagaku Kaishi 1994; 68: 979-981

24 Meguri H, Katakawa J, Tetsumi T, Uchida S, Sumi M, Katai M, Terai T, Fukumoto K. Simple and rapid determination of grayanotoxins by high-performance liquid chromatography. Shoyakugaku Zashi 1993; 47: 429-433

25 Lee S, Choi Y, Lee K, Cho T, Kim J, Son Y, Park J, Im S, Choi H, Lee D. Determination and monitoring of grayanotoxins in honey using LC-MS/MS. Korean J Food Sci Tech 2008; 40: 8-14

26 von Kürten S, Pachaly P, Zymalkowski F, Snatzke G. Neue Grayanotoxine in Blattextrakten von Rhododendron ponticum. Ein Beitrag zur Stereochemie der Grayanotoxine. Liebigs Ann Chem 1970; 741: 142-152

27 Humphreys DJ, Stodulski JBJ. Detection of andromedotoxins for the diagnosis of Rhododendron poisoning in animals. J Appl Tox 1986; 6: 121-122

28 Morel S, Landreau A, Nguyen VH, Derbré S, Grellier P, Pape P, Pagniez F, Litaudon M, Richomme P. Preparative isolation, fast centrifugal partition chromatography purification and biological activity of cajaflavanone from Derris ferruginea stems. Phytochem Anal 2011; 23: 152 158

29 Lechtenberg $M$, Schepmann D, Niehues $M$, Hellenbrand N, Wünsch B, Hensel A. Quality and functionality of saffron: quality control, species assortment and affinity of extract and isolated saffron compounds to NMDA and $\sigma 1$ (sigma-1) receptors. Planta Med 2008; 74: 764-772

30 Bringmann G, Lang G, Steffens S, Schaumann K. Petrosifungins A and B, novel cyclodepsipeptides from a sponge-derived strain of Penicillium brevicompactum. J Nat Prod 2004; 67: 311-315

31 Michaelis G, Tschetsch O. German Gene Bank Rhododendron. Available at http://www.lwk-niedersachsen.de/index.cfm/portal/70/nav/1485/ article/18096.html. Accessed July 21, 2014

32 Burke JW, Doskotch W. High field 1H- and 13C-NMR assigments of grayanotoxins I, IV, and XIV isolated from Kalmia angustifolia. J Nat Prod 1990; 53: 131-137

33 Tallent WH, Riethof, ML, Horning EC. Studies on the occurrence and structure of acetylandromedol (andromedotoxin). J Am Chem Soc 1957; 79: 4548-4554

34 Nahrstedt A. Cover text and editorial. Planta Med 2010; 14: 14

35 Harmannstein D. Phytochemical and toxicological research of Rhododendron ferrugineum L. [diploma thesis]. Vienna: University of Vienna; 2008

36 International Conference on Harmonization of Technical Requirements for Registration of Pharmaceuticals for Human Use; ICH Harmonized Tripartite Guideline; Validation of Analytical Procedures: Text and Methodology Q2(R1); Finalised Guidelines: October 1994/November 1996

37 MandelJ. The statistical analysis of experimental data. New York: Wiley \& Sons; 1964 